Supporting information

\title{
Polyanionic amphiphilic dendritic polyglycerols as broad-spectrum viral inhibitors with a virucidal mechanism
}

Ehsan Mohammadifar ${ }^{+}, 1$, Matteo Gasbarri ${ }^{+}, 2$, Valeria Cagno $^{3}$, Katharina Achazi ${ }^{1}$, Caroline Tapparel $^{3}$, Rainer Haag ${ }^{*}, 1$, and Francesco Stellacci*,2

${ }^{1}$ Institute of Chemistry and Biochemistry, Freie Universität Berlin, Takustr. 3, 14195 Berlin, Germany.

${ }^{2}$ Institute of Materials, École Polytechnique Fédérale de Lausanne (EPFL), Lausanne 1015, Switzerland.

${ }^{3}$ Department of Microbiology and Molecular Medicine, University of Geneva, Geneva 1211, Switzerland.

${ }^{+} \mathrm{EM}$ and MG contributed equally to this work.

*E-mail: haag@chemie.fu-berlin.de

*E-mail: francesco.stellacci@epfl.ch 
Dendritic polyglycerol (dPG) $10 \mathrm{kDa}$ was synthesized using the previously reported procedure ${ }^{1}$ characterized by NMR and GPC $\left(\mathrm{H}_{2} \mathrm{O}\right)$ for the determination of absolute molecular weights and polydispersity index. The degree of branching (DB) was calculated using inverse gated (IG) ${ }^{13} \mathrm{C}$ NMR as reported in literature. ${ }^{2}$

$\operatorname{GPC}\left(\mathrm{H}_{2} \mathrm{O}\right): \mathrm{M}_{\mathrm{n}}=9.6 \mathrm{kDa}, \mathrm{M}_{\mathrm{w}}=12.6 \mathrm{kDa}, \mathrm{D}=1.31$

Degree of branching (DB) as determined by $\mathrm{IG}{ }^{13} \mathrm{CNMR}=59 \%$
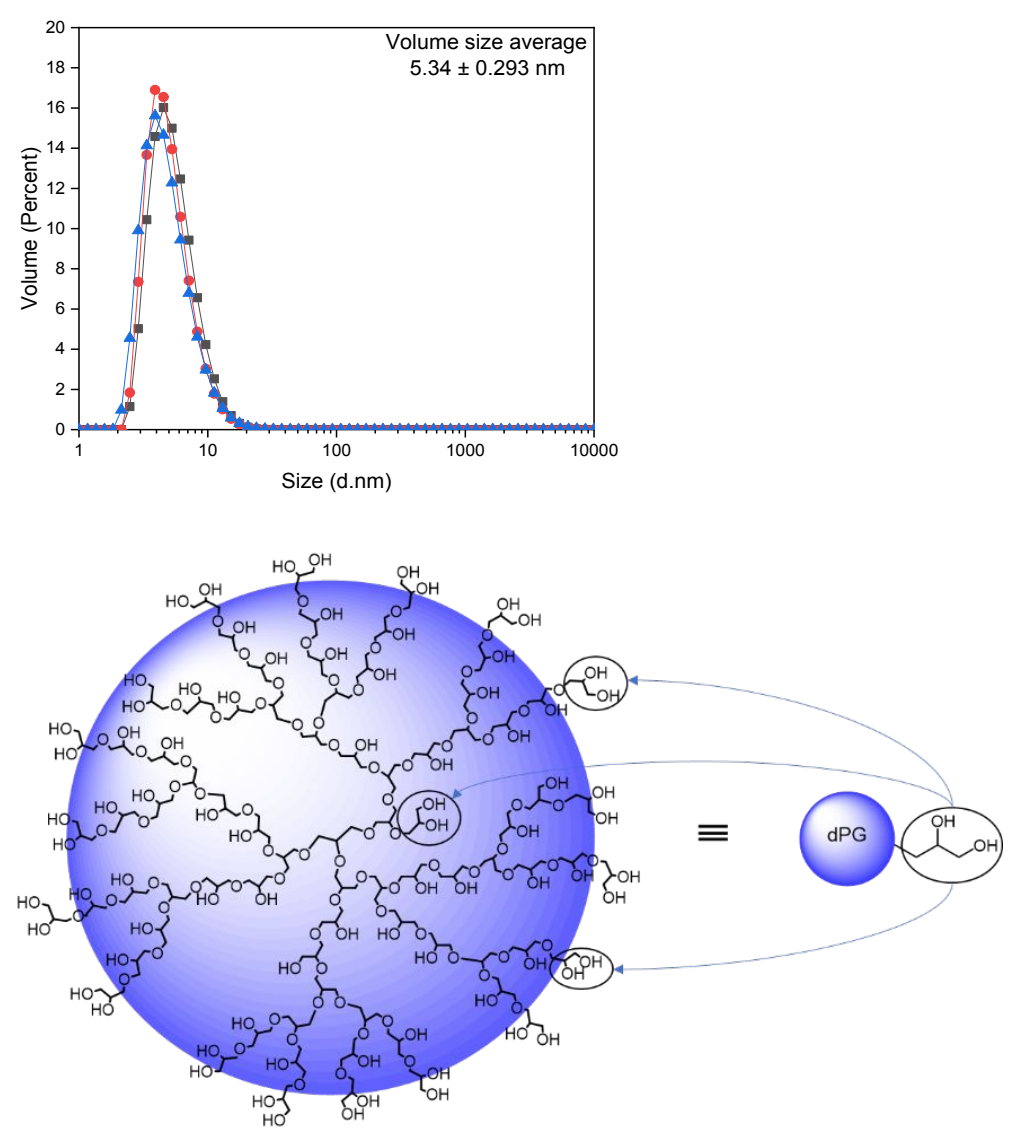

Figure S1. On top of the figure: DLS measurement of dPG in phosphate buffer at concentration $1 \mathrm{mg} / \mathrm{mL}$. The results are for three measurement series (indicated by triangles, circles and squares). At the bottom: Chemical structure of dendritic polyglycerol (right) and the representative scheme for dPG (right). The hydroxyl groups in the right scheme are representative for all hydroxyl groups in $\mathrm{dPG}$ structure. 


\section{Synthesis of dPG-allyl}

dPG (200 mg, $2.69 \mathrm{mmol} \mathrm{OH}$ to be functionalized) was dried at $60{ }^{\circ} \mathrm{C}$ overnight under high vacuum. Dried dPG was dissolved in dry DMF $(20 \mathrm{~mL})$ and cooled to $0{ }^{\circ} \mathrm{C}$. To the stirred solution of dPG in dry DMF at $0{ }^{\circ} \mathrm{C}, \mathrm{NaH}(129.12 \mathrm{mg}, 5.38 \mathrm{mmol}, 2$ eq.) was added. After addition ice bath was removed and the temperature of the reaction mixture was allowed to reach room temperature. The reaction mixture was allowed to stir for 1 hours at room temperature and 1 hours at $40{ }^{\circ} \mathrm{C}$ and then cooled down again by using ice bath. The allyl bromide $(465 \mu \mathrm{L}, 5.38 \mathrm{mmol}$, 2.0 eq.) in dry DMF (1 mL) was added dropwise to the reaction mixture using a syringe. The ice bath was removed and after stirring for 24 hours at $40{ }^{\circ} \mathrm{C}$ the reaction was quenched by addition of methanol and the resulting mixture was dialyzed in $\mathrm{MeOH}$ to afford dPG-allyl ( $\mathrm{DF}=100 \%$ ). Degree of allylation was quantified by ${ }^{1} \mathrm{H} \mathrm{NMR}$ in $\mathrm{CD}_{3} \mathrm{OD}$. Only for the synthesis of precursor for dPG-1, the dPG-ally with DF $=2 \%$ was synthesized.
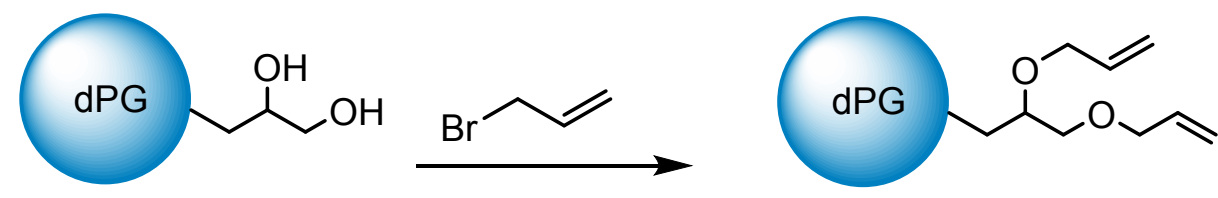

Dry DMF, $\mathrm{NaH}$

$50{ }^{\circ} \mathrm{C}$

Figure S2. Synthetic route for preparation the of dPG-allyl. 


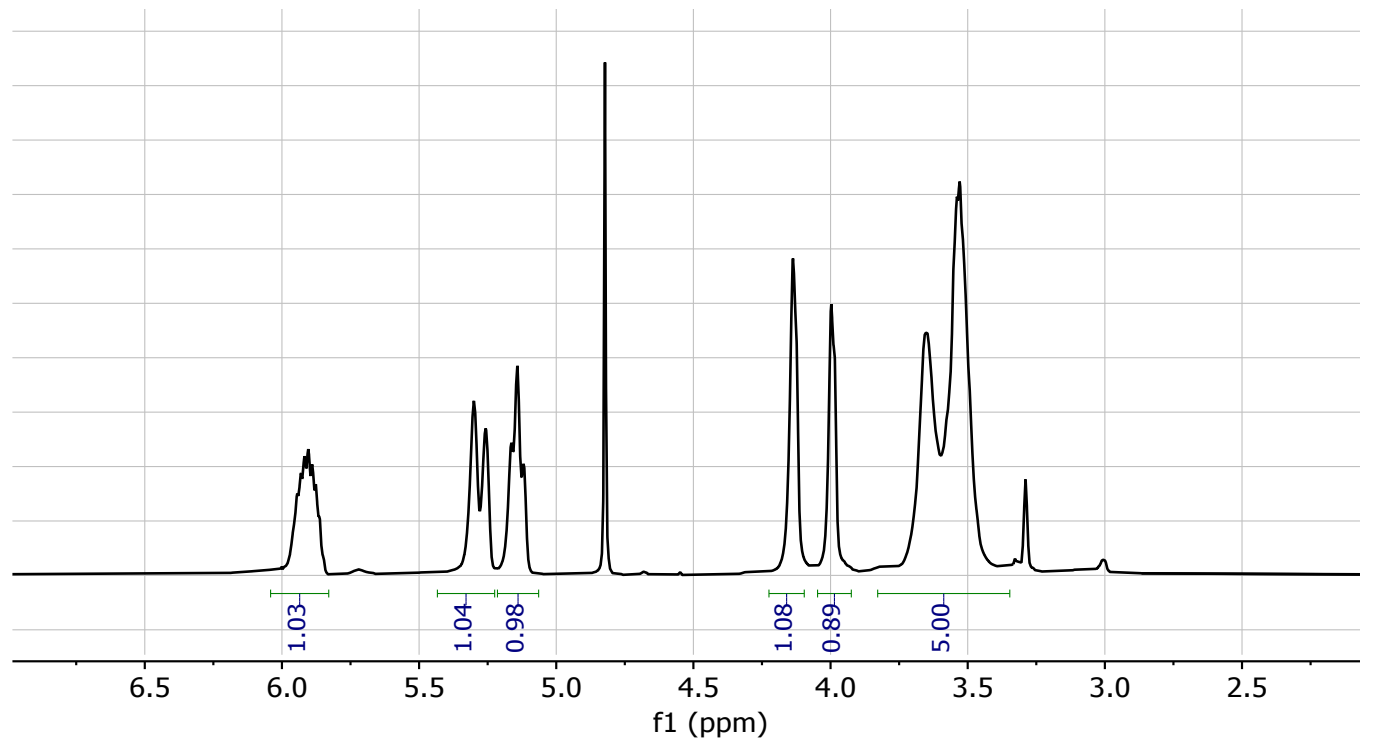

Figure S3. The degrees of functionalization (DF) in the different reactions were confirmed by ${ }^{1} \mathrm{H}$ NMR of the pure product correlating the allyl protons at 5.9 -5.8 ppm with the polyglycerol backbone protons $(3.7-3.4)$.

\section{Synthesis of 11-mercapto-1-undecanesulfonate (MUS)}

In order to functionalize the dPG-allyl, 11-mercapto-1-undecanesulfonate (MUS) was synthesized through a three-step reaction following a reported procedure. ${ }^{3}$

Sodium undec-10-enefulfonate: 11-bromo-1-undecene (25 mL, $111.975 \mathrm{mmol})$, Sodium Sulfite $\mathrm{Na}_{2} \mathrm{SO}_{3}(28.75 \mathrm{~g}, 227.92 \mathrm{mmol})$ benzyltriethyl-ammonium bromide $(10 \mathrm{mg})$ were added to a mixture of $200 \mathrm{~mL}$ methanol and $450 \mathrm{~mL}$ DI-water in a $1 \mathrm{~L}$ round bottom flask. The mixture was refluxed at $102^{\circ} \mathrm{C}$ for $48 \mathrm{~h}$. The mixture was extracted with diethyl ether 5 times, $(5 \times 400 \mathrm{ml})$, and the aqueous phase was evaporated in a rotary evaporator. The white powder was dried under high vacuum, suspended in pure ethanol and filtered. The solution was evaporated, and the process was repeated twice, to decrease the amount of inorganic salts. Usually, about $33 \mathrm{~g}$ of white, methanol soluble power was collected at this scale. 
Sodium 11-acetylthio-undecanefulfonate: Sodium undec-10-enefulfonate (33 g, $147.807 \mathrm{mmol})$ was dissolved in $500 \mathrm{ml}$ of methanol. The solution should be clear in order to have high yield. The precipitation should be removed by fliteration. A 2.6 times excess of thioacetic acid $(27.324 \mathrm{~mL}$, $384.3 \mathrm{mmol}$ ) was added to the solution and stirred in front of a UV lamp overnight (12h). The solution was evaporated in a rotary evaporator until the solid residue turned orange-red. The solid was washed with diethyl ether, until no colored material could be removed. The solid was dried under high vacuum, and then dissolved in methanol producing a yellow solution. About $3 \mathrm{~g}$ of carbon black was added to the solution, vigorously mixed, and the mixture was filtered through celite in a fluted filter paper. The filtered solution was clear, the solvent completely evaporated and about $35 \mathrm{~g}$ of white solid was collected.

11-mercapto-1-undecanesulfonate (MUS): Sodium 11-acetylthio-undecanefulfonate was refluxed at in $400 \mathrm{~mL}$ of $1 \mathrm{M} \mathrm{HCl}$ for $12 \mathrm{~h} .200 \mathrm{~mL}$ of $1 \mathrm{M} \mathrm{NaOH}$ was added to the final solution, additional $400 \mathrm{~mL}$ of DI-water was added to create a $1 \mathrm{~L}$ volume. The clear solution was kept at $4^{\circ} \mathrm{C}$ and crystallized overnight. The viscous white product was centrifuged down in $50 \mathrm{~mL}$ falcon tubes, and dried under high vacuum. $12 \mathrm{~g}$ of methanol soluble MUS is collected from this purification step. More material can be extracted from the supernatant of the centrifugation step, by reducing volume and keeping it at $4^{\circ} \mathrm{C}$. The successful synthesis of MUS was proved by ${ }^{1} \mathrm{HNMR}$ and ESIMS analysis (ESI-MS m/z $313.08(\mathrm{M}+\mathrm{Na})$ and $\mathrm{m} / \mathrm{z} 601.17(2 \mathrm{M}+\mathrm{Na})$ for dimer which is formed due to disulfide bond formation). 


$$
\text { benzyltriethyl amonium }
$$

Figure S4. Synthetic route for the synthesis of 11-mercapto-1-undecanesulfonate (MUS).

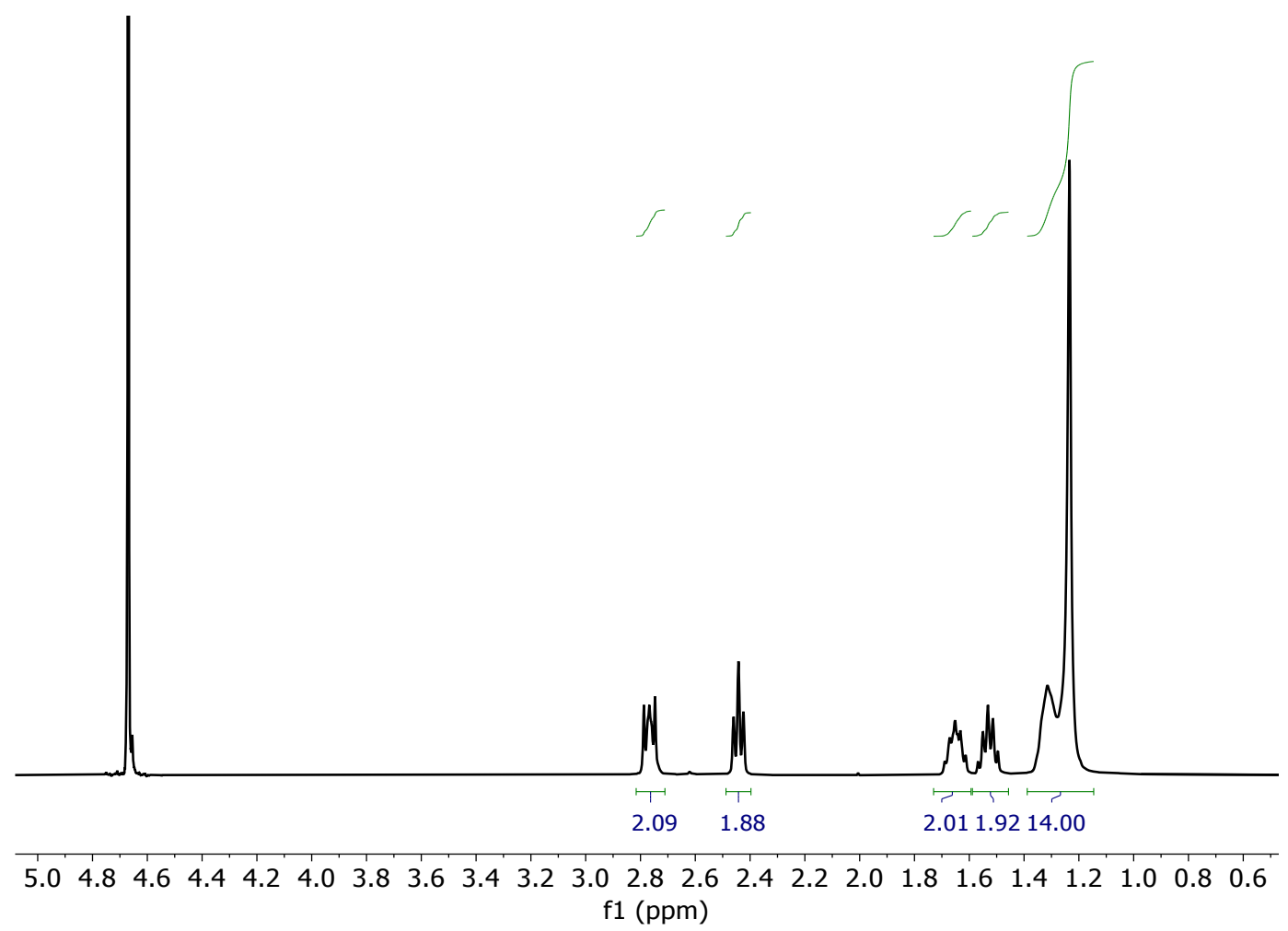

Figure S5. ${ }^{1} \mathrm{HNMR}$ of 11-mercapto-1-undecanesulfonate (MUS). 


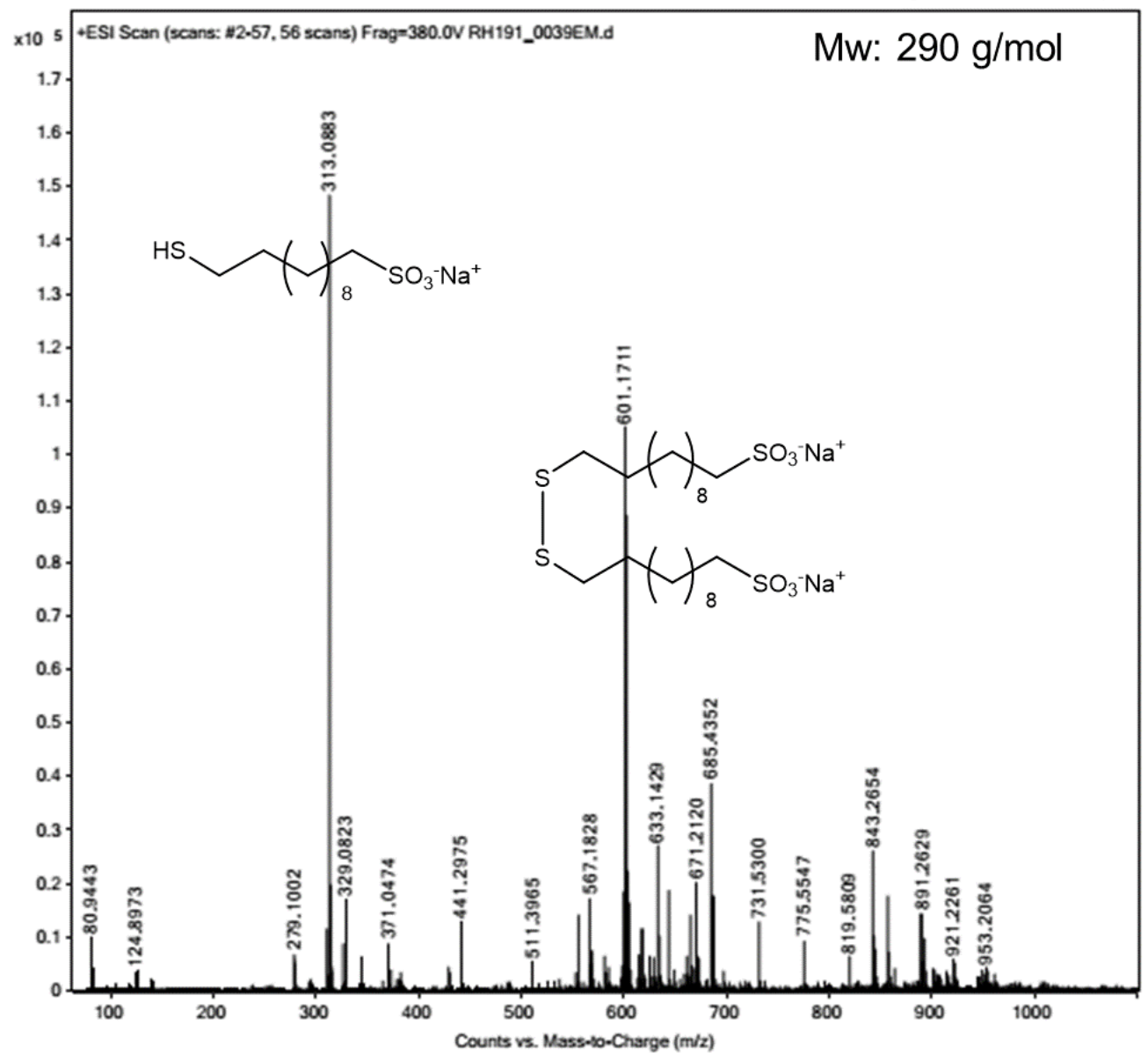

Figure S6. ESI-MS (m/z) of 11-mercapto-1-undecanesulfonate (MUS).

\section{Synthesis of dPG-1, dPG-2, dPG-3}

dPG-allyl (DF=2) (50 mg, $0.01 \mathrm{mmol}$ of allyl group) for dPG-1 and dPG-allyl (DF=100) (50 mg, 0.67 mmol of allyl group) for dPG-2 and dPG-3 have been used as precursor for the thiol-ene click reaction. Corresponding dPG-allyl and (11-mercapto-1-undecanesulfonate) with the determined molar ratio to the allyl groups were dissolved in methanol (5 mL). 2,2-dimethoxy-2phenylacetophenone (DMPA) as radical initiator $(50 \mathrm{mg}, 0.19 \mathrm{mmol})$ and a catalytic amount of tris(2-carboxyethyl)phosphine hydrochloride (TCEP-HCl) was added to the reaction to avoid oxidation of the thiol intermediate. In the case precipitation, few drops of water were added to 
dissolve the precipitation and obtain a clear solution. The solution was degassed by flushing argon through the reaction mixture for 10 minutes. The reaction mixture was stirred and irradiated with UV light using a high pressure UV lamp at room temperature for 5 hours. The reaction mixture was dialyzed (MWCO $2 \mathrm{kDa}$ ) against methanol/water mixture to remove the TCEP.HCl, DMPA and excess of unreacted thiol compound. The successful formation of product was confirmed by ${ }^{1} \mathrm{HNMR}$ of pure product by correlating the aliphatic protons of ligands at $1.5-1.00 \mathrm{ppm}$ with the polyglycerol backbone protons at 3.7-3.2 ppm. In addition, elemental analysis was used for the sulfur content measurement confirming the click reaction.

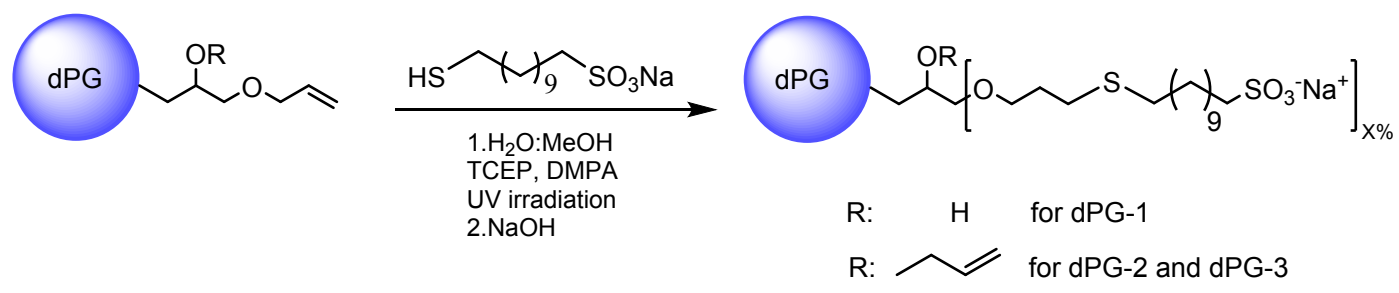

Figure S7. Synthetic route for preparation of the dPG-1 $(X=2)$, dPG-2 $(X=50)$ and dPG-3 $(X=$ 85). 


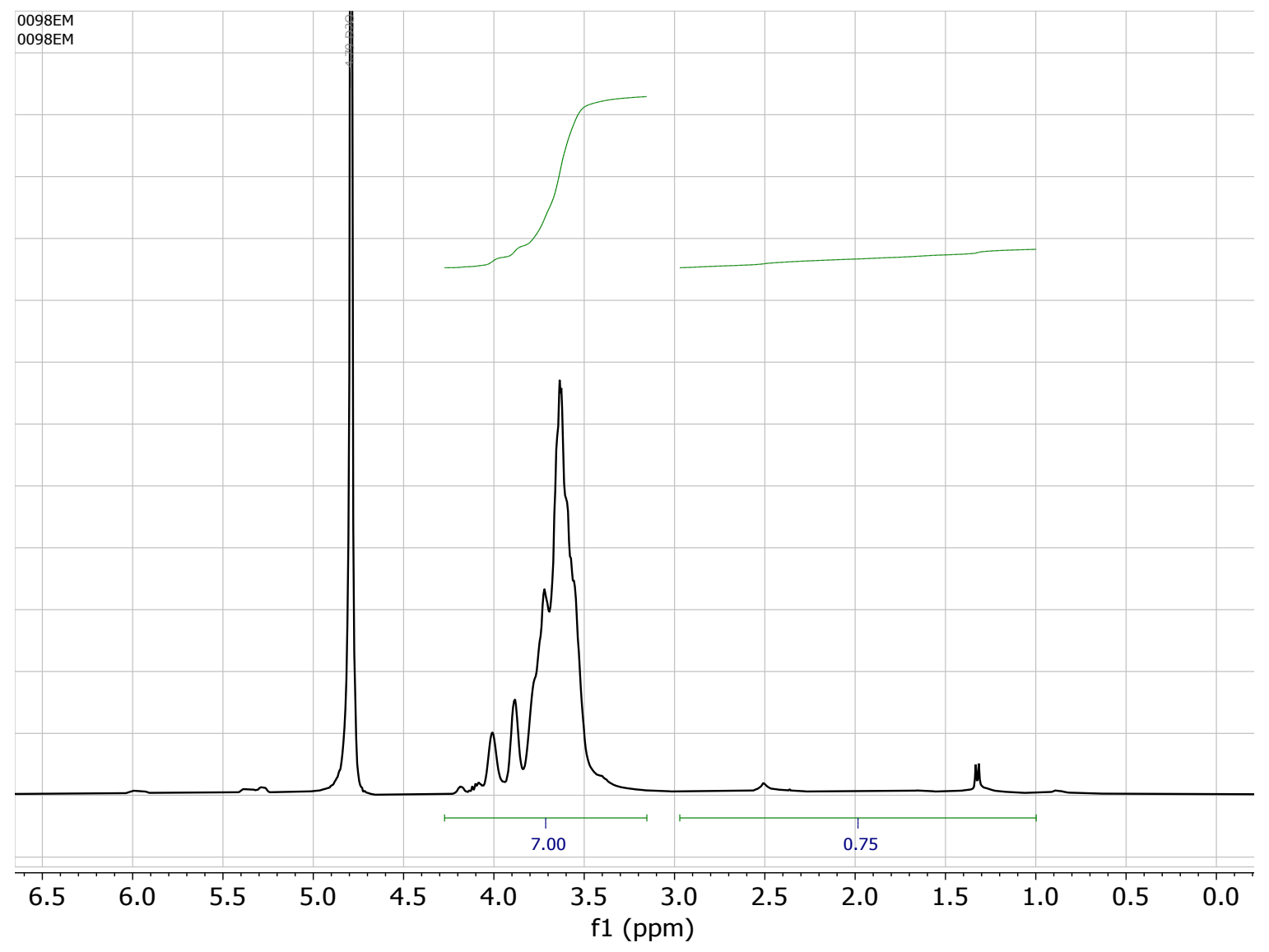

Figure S8. ${ }^{1} \mathrm{HNMR}$ of $\mathrm{dPG}-1$ in $\mathrm{D}_{2} \mathrm{O}$. dPG-1 was functionalized with 11-mercapto-1undecanesulfonate (MUS) with degree of functionalization of $2 \%$. 


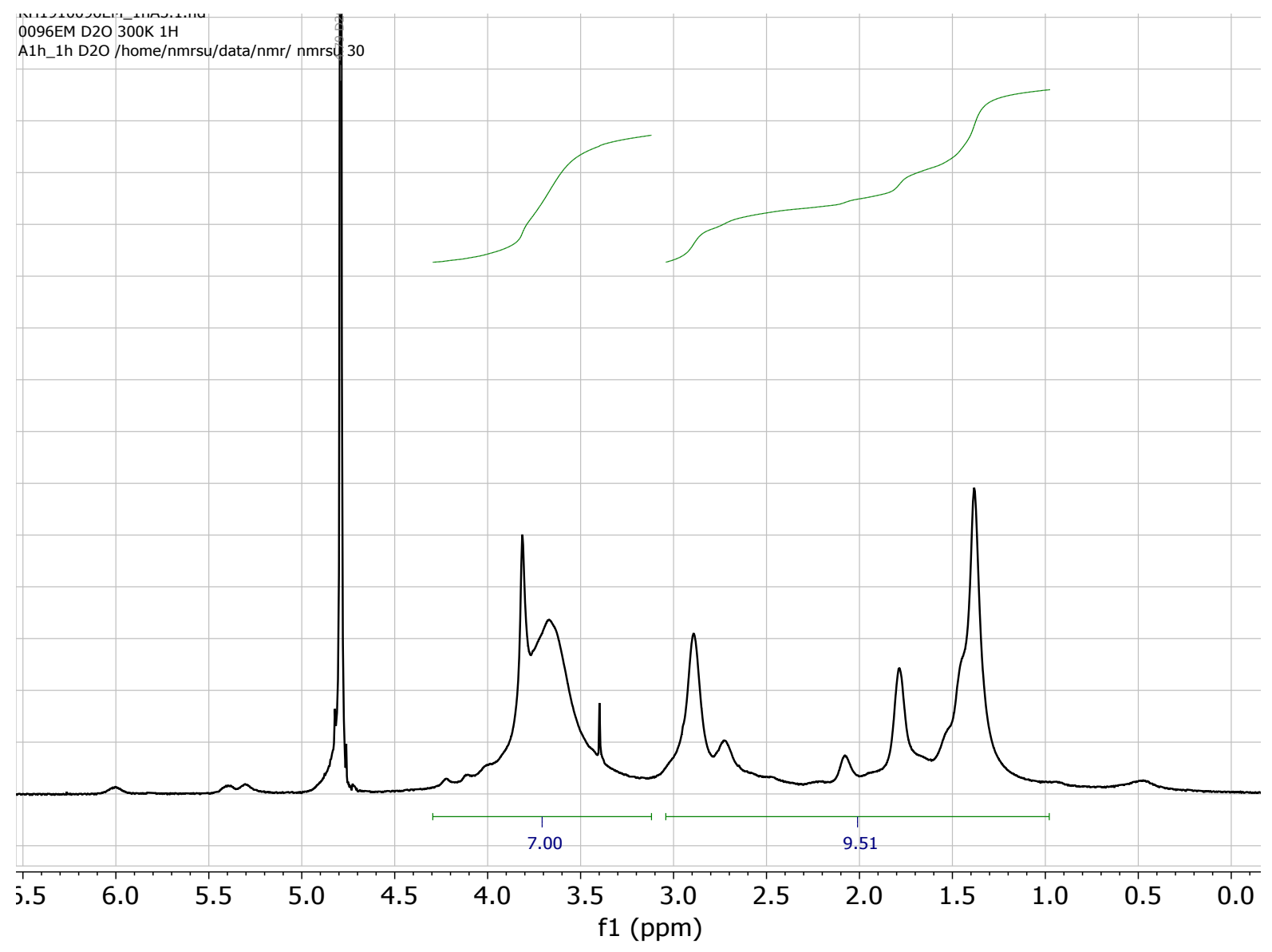

Figure S9. ${ }^{1} \mathrm{HNMR}$ of $\mathrm{dPG}-2$ in $\mathrm{D}_{2} \mathrm{O}$. dPG-2 was functionalized with 11-mercapto-1undecanesulfonate (MUS) with degree of functionalization of $50 \%$. 


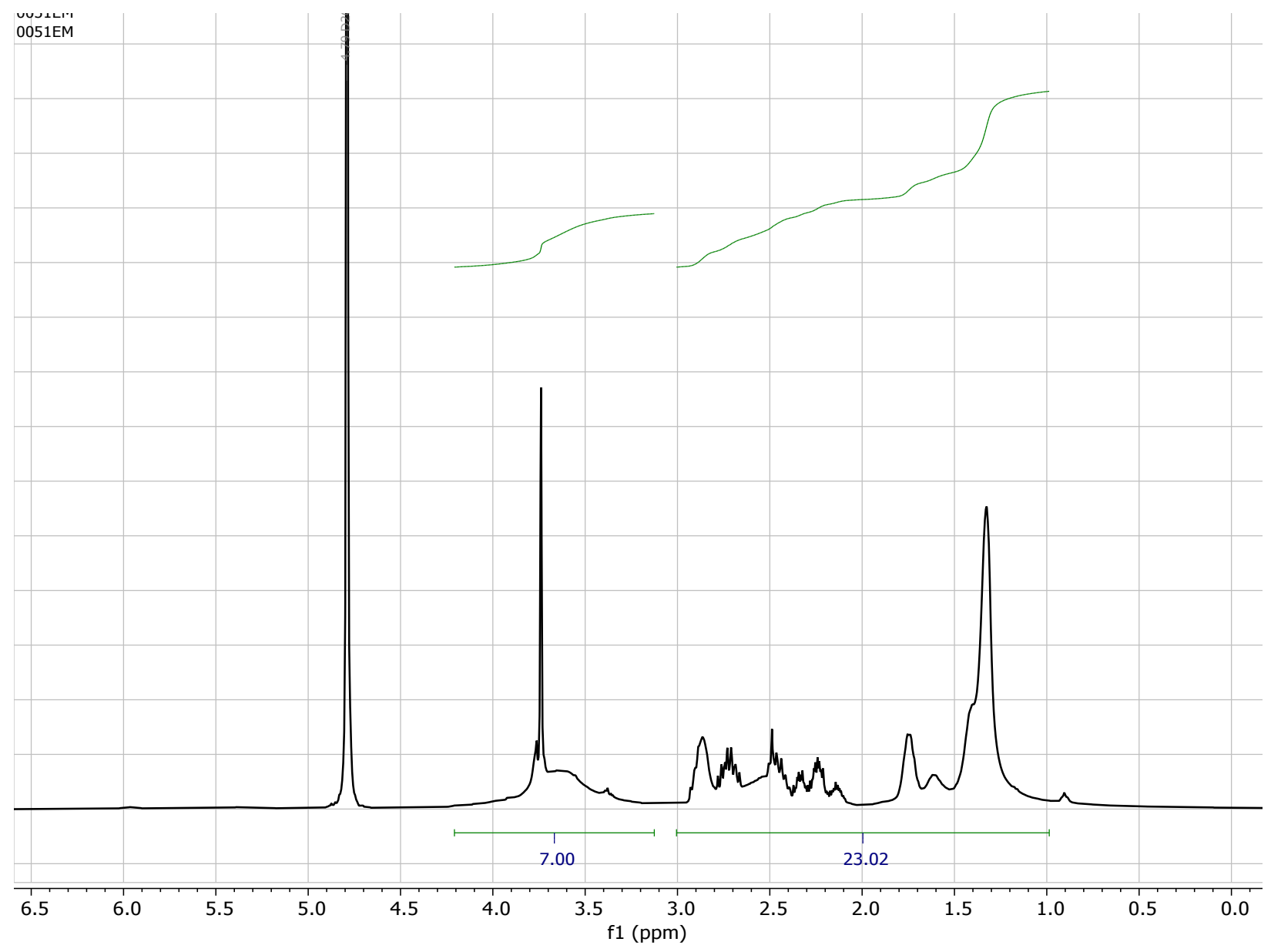

Figure S10. ${ }^{1} \mathrm{HNMR}$ of $\mathrm{dPG}-3$ in $\mathrm{D}_{2} \mathrm{O}$. dPG-3 was functionalized with 11-mercapto-1undecanesulfonate (MUS) with degree of functionalization of $85 \%$. 
Table S1. Elemental analysis and molecular weight $(\mathrm{Mn})$ of functionalized $\mathrm{dPG}$. ${ }^{*} \mathrm{Mn}$ is calculated based on the degree of functionalization of each dendritic polyglycerol which is determined by ${ }^{1} \mathrm{HNMR}$, considering the Mn of starting $\mathrm{dPG}$ core $10 \mathrm{kDa}$.

\begin{tabular}{|c|c|c|c|}
\hline & $\mathrm{dPG}-1$ & $\mathrm{dPG}-2$ & $\mathrm{dPG}-3$ \\
\hline $\mathrm{C} \%$ & 47.5 & 53.4 & 46.0 \\
\hline $\mathrm{H} \%$ & 7.5 & 7.9 & 7.4 \\
\hline $\mathrm{N} \%$ & 0.0 & 0.0 & 0.0 \\
\hline $\mathrm{S} \%$ & 1.0 & 6.6 & 9.6 \\
\hline $\mathrm{Mn}(\mathrm{kDa}) *$ & 11 & 29 & 40 \\
\hline
\end{tabular}

\section{Synthesis of dPG-4}

dPG-allyl (DF=100) (50 mg, $0.67 \mathrm{mmol}$ of allyl group) and the 11-Mercapto-1-undecanol (80 mg, $0.39 \mathrm{mmol}$ ) were dissolved in methanol (5 mL). 2,2-dimethoxy-2-phenylacetophenone (DMPA) as radical initiator (50 mg, $0.19 \mathrm{mmol})$ and a catalytic amount of tris(2-carboxyethyl)phosphine hydrochloride (TCEP-HCl) was added to the reaction to avoid oxidation of the 11-Mercapto-1undecanol. The solution was degassed by flushing argon through the reaction mixture for 10 minutes. The reaction mixture was stirred and irradiated with UV light using a high pressure UV lamp at room temperature for 4 hours. A small aliquot of the reaction solution was taken for characterization and the rest of allyl groups were quenched by addition of excess amount of 1propanthiol. The reaction mixture was further stirred and irradiated with UV light for 4 more hours. At the end, the reaction mixture was dialyzed (MWCO $2 \mathrm{kDa}$ ) against methanol to remove the impurities and unreacted compounds. The degrees of functionalization was determined by ${ }^{1} \mathrm{H}$ 
NMR of the pure product by correlating the aliphatic protons at 1.8-1.1 ppm with the polyglycerol backbone protons $(4.0$ - 3.2).

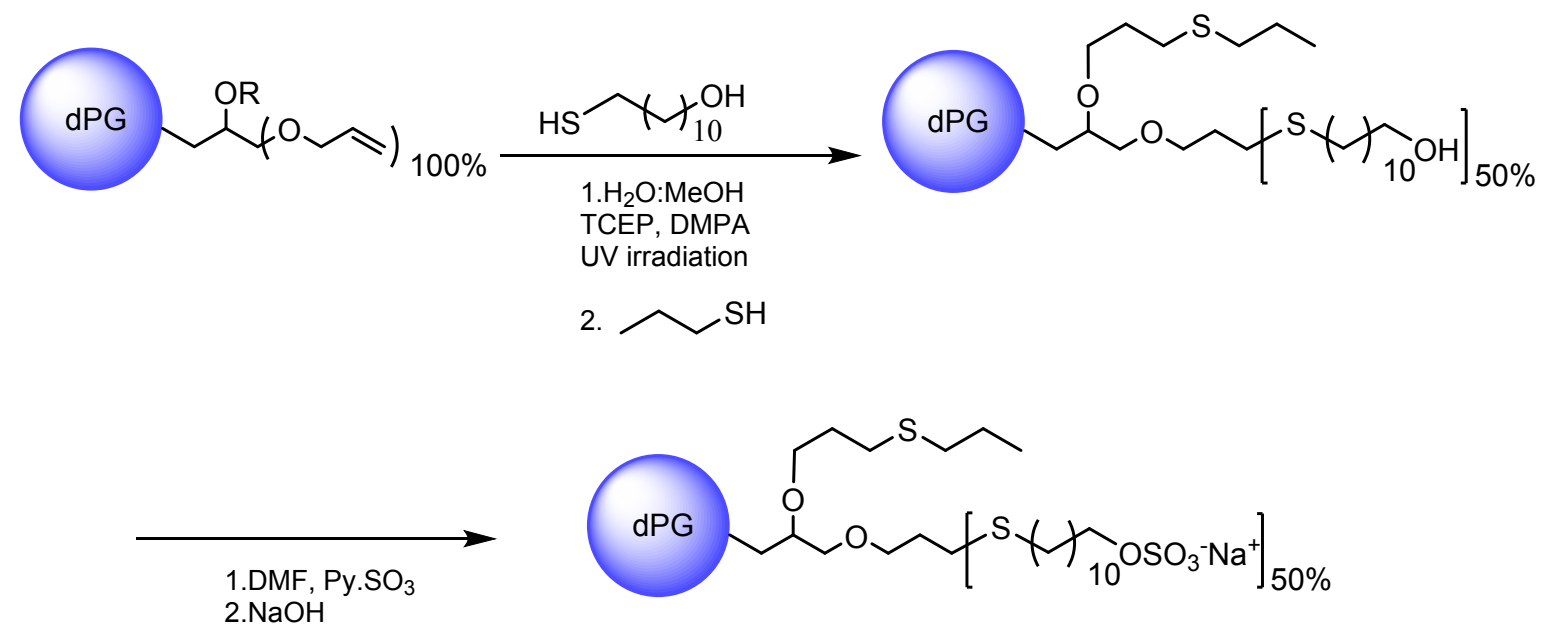

Figure S11. Synthetic route for preparation of the dPG-4. 


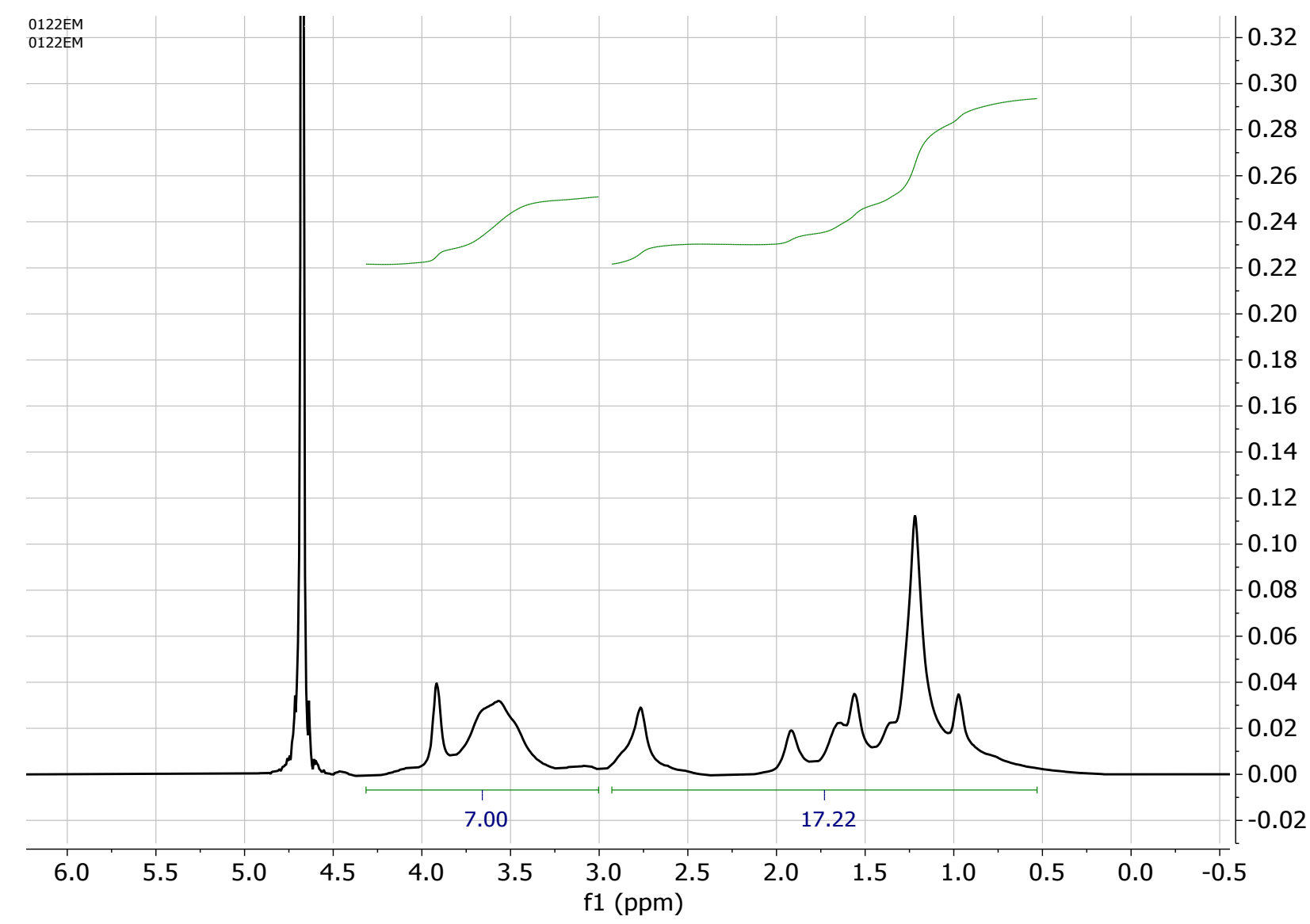

Figure S12. ${ }^{1} \mathrm{HNMR}$ of dPG-4 in $\mathrm{D}_{2} \mathrm{O}$. 
Table S2. Elemental analysis and molecular weight (Mn) of dPG-4. * Mn is calculated based on the degree of functionalization of each dendritic polyglycerol which is determined by ${ }^{1} \mathrm{HNMR}$, considering the Mn of starting $\mathrm{dPG}$ core $10 \mathrm{kDa}$.

\begin{tabular}{|c|c|}
\hline & dPG-4 \\
\hline $\mathrm{C} \%$ & 40.6 \\
\hline $\mathrm{H} \%$ & 7.1 \\
\hline $\mathrm{N} \%$ & 0.0 \\
\hline $\mathrm{S} \%$ & 12.8 \\
\hline $\mathrm{Mn}(\mathrm{kDa})^{*}$ & 35 \\
\hline
\end{tabular}

\section{Synthesis of dPG-5}

$\mathrm{dPG}$ (400 $\mathrm{mg}, 5.4 \mathrm{mmol} \mathrm{OH}$ to be functionalized) was dried at $60^{\circ} \mathrm{C}$ overnight under high vacuum. Dried dPG was dissolved in dry DMF (30 mL). To the stirred solution of dPG in dry DMF at room temperature, $\mathrm{NaH}(259.17 \mathrm{mg}, 10.8 \mathrm{mmol}, 2$ eq.) was added. The reaction mixture was allowed to stir for 1 hours at room temperature and 1 hours at $40{ }^{\circ} \mathrm{C}$ and then cooled down by using an ice bath. 11-Bromo-1-undecanol (2 g, $8.1 \mathrm{mmol}, 1.5$ eq. $)$ in dry DMF $(5 \mathrm{~mL})$ was added dropwise to the reaction mixture using a syringe. The ice bath was removed and the reaction was stirred $1 \mathrm{~h}$ at room temperature and further 48 hours at $40{ }^{\circ} \mathrm{C}$. The reaction was quenched by addition of methanol and the resulting mixture was dialyzed in methanol/chloroform mixture for 2 days to remove the unreacted compounds. The product $\left(\mathrm{dPG}-\mathrm{C}_{11}-\mathrm{OH}\right)$ was obtained as a white and highly 
viscose compound after evaporation of methanol by rotary evaporator. Degree of functionalization was quantified by ${ }^{1} \mathrm{H}$ NMR in DMF- $\mathrm{d}_{6}$.

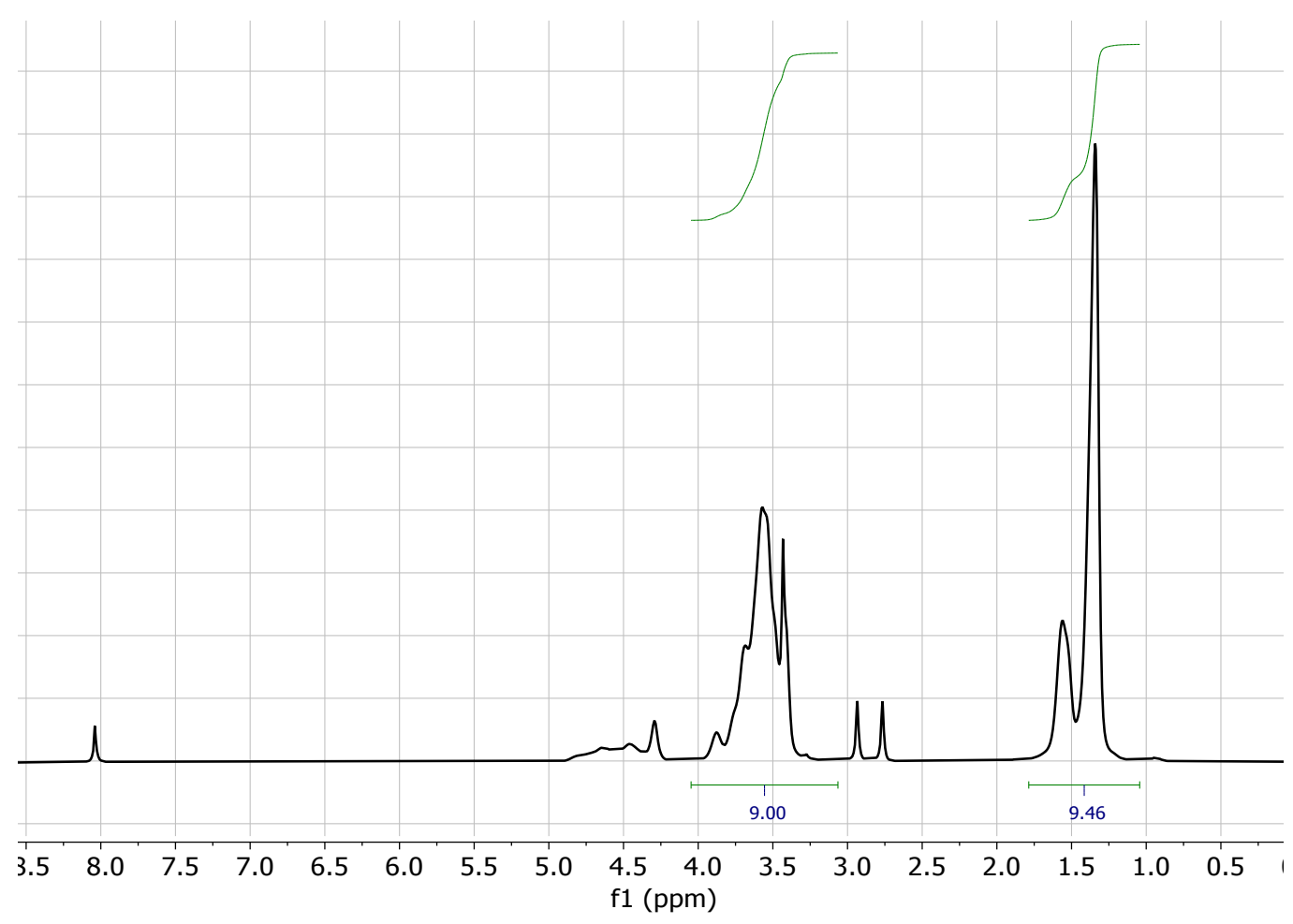

Figure S12. ${ }^{1} \mathrm{HNMR}$ of dPG-5 (before sulfation reaction) in DMF-d.

In the next step both types of hydroxyl groups (on the dPG surface and at the end of alkyl chain) were sulfated through the reaction with pyridine sulfur trioxide $\left(\mathrm{Py} \cdot \mathrm{SO}_{3}\right)$ complex. For this aim, dPG-C $\mathrm{C}_{11}-\mathrm{OH}$ (700 mg, $5.4 \mathrm{mmol} \mathrm{OH}$ to be sulfated) was dried overnight at $60{ }^{\circ} \mathrm{C}$ under vacuum. Dried dPG-C $\mathrm{C}_{11}-\mathrm{OH}$ was dissolved in dry DMF $(30 \mathrm{~mL})$ under inert atmosphere. To the stirred solution of dPG- $\mathrm{C}_{11} \mathrm{-OH}$ in dry DMF at $60{ }^{\circ} \mathrm{C}, \mathrm{Py} \cdot \mathrm{SO}_{3}(1.289 \mathrm{~g}, 8.1 \mathrm{mmol}, 1.5$ eq.) in dry DMF (5 $\mathrm{mL}$ ) was added dropwise. The reaction mixture was allowed to stir at $60^{\circ} \mathrm{C}$ overnight. The reaction was quenched with water, and the $\mathrm{pH}$ was adjusted to 8 by addition of $\mathrm{NaOH}$ solution. The mixture was then dialysed against brine using an ever-decreasing $\mathrm{NaCl}$ concentration for 2 days, until the medium was changed with distilled water and dialysis continued for 2 more days. ${ }^{4}$ The solvent 
was decreased under reduced pressure and the product was obtained as a white powder after lyophilisation. The degrees of functionalization (DF) in the different reactions were determined by ${ }^{1} \mathrm{H}$ NMR of the pure product correlating the aliphatic protons at 1.8-1.1 ppm with the polyglycerol backbone protons (4.4 - 3.2).

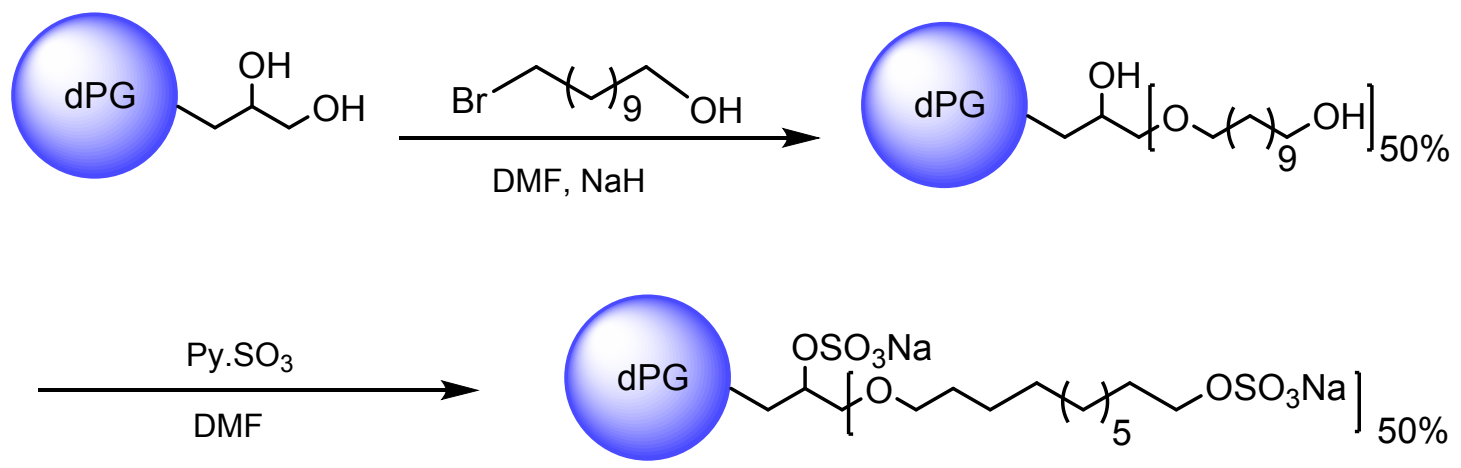

Figure S13. Synthetic route for preparation of the dPG-5. 


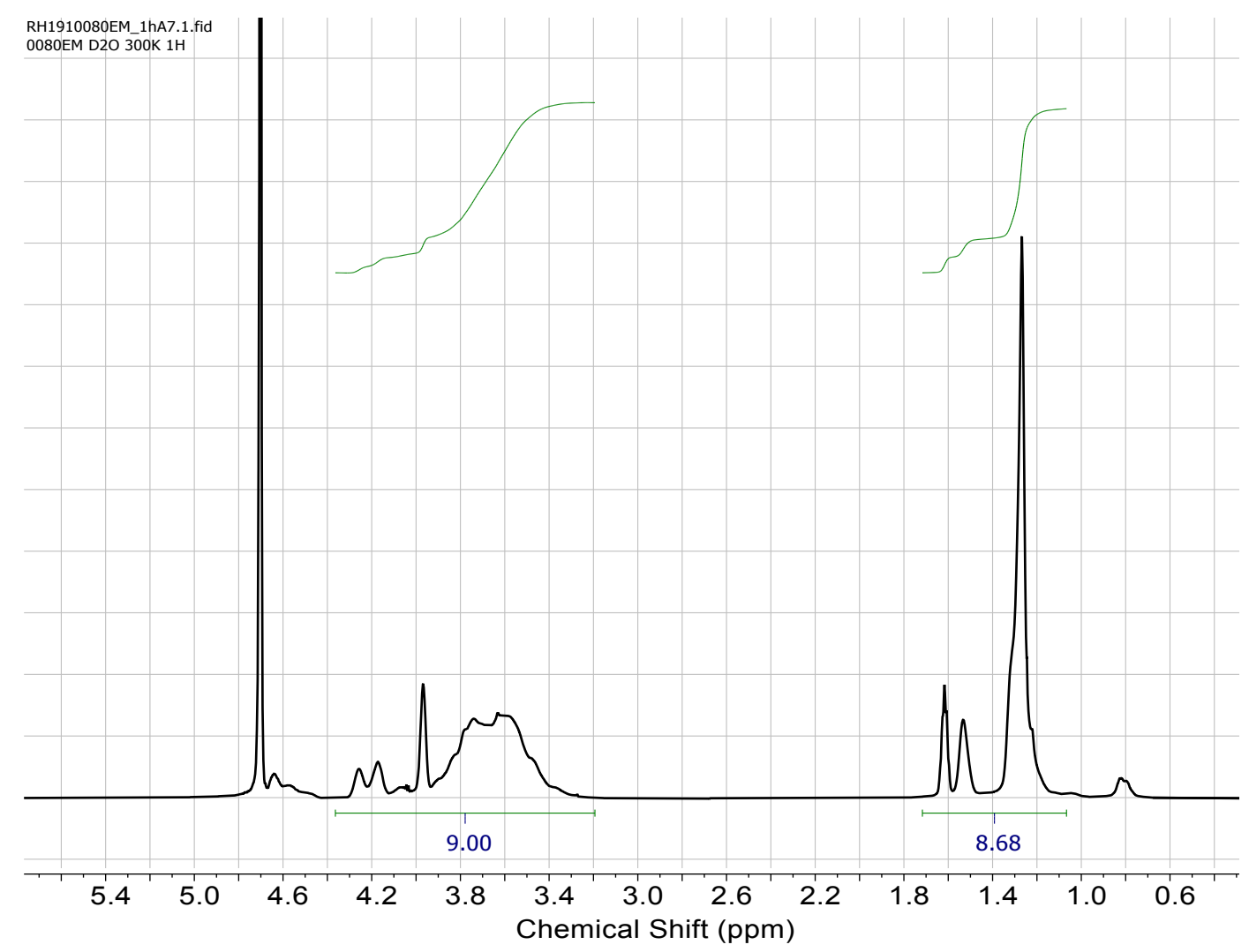

Figure S14. ${ }^{1} \mathrm{HNMR}$ of dPG-5 in $\mathrm{D}_{2} \mathrm{O}$. 
Table S3. Elemental analysis and molecular weight (Mn) of dPG-5 before and after sulfation. * $\mathrm{Mn}$ is calculated based on the degree of functionalization of dPG-5 which is determined by ${ }^{1} \mathrm{HNMR}$, considering the Mn of starting $\mathrm{dPG}$ core $10 \mathrm{kDa}$. Increase in the carbon and hydrogen contents of dPG-5 (before sulfation) compared to dPG is due to the functionalization with the eleven-carbon alkyl chain. Additionally, the decrease in carbon and hydrogen contents in dPG-5 together with sulfur content is confirming the sulfation reaction.

\begin{tabular}{|c|c|c|c|}
\hline & $\mathrm{dPG}$ & $\mathrm{dPG}-5$ (before sulfation) & dPG-5 (after sulfation) \\
\hline $\mathrm{C} \%$ & 47.4 & 62.2 & 32.6 \\
\hline $\mathrm{H} \%$ & 7.8 & 10.0 & 5.7 \\
\hline $\mathrm{N} \%$ & 0.0 & 0.0 & 0.0 \\
\hline $\mathrm{S} \%$ & 0.0 & 0.0 & 12.1 \\
\hline $\mathrm{Mn}(\mathrm{kDa}) *$ & 9.6 & 23 & 36 \\
\hline
\end{tabular}

\section{Synthesis of dPG-6}

$\mathrm{dPG}$ (400 mg, $5.4 \mathrm{mmol} \mathrm{OH}$ to be functionalized) was dried at $60^{\circ} \mathrm{C}$ overnight under high vacuum. Dried dPG was dissolved in dry DMF $(30 \mathrm{~mL})$. To the stirred solution of dPG in dry DMF at room temperature, $\mathrm{NaH}$ (259.17 mg, $10.8 \mathrm{mmol}, 2$ eq.) was added. The reaction mixture was allowed to stir for 1 hours at room temperature and 1 hours at $40{ }^{\circ} \mathrm{C}$ and then cooled down by using an ice bath. 1-Bromoundecane ( $2 \mathrm{~g}, 8.5 \mathrm{mmol}, 1.5$ eq.) in dry DMF ( $5 \mathrm{~mL}$ ) was added dropwise to the reaction mixture using a syringe. The ice bath was removed and the reaction was stirred $1 \mathrm{~h}$ at room temperature and further 48 hours at $40{ }^{\circ} \mathrm{C}$. The reaction was quenched by addition of methanol and the resulting mixture was dialyzed in methanol/chloroform mixture for 2 days to remove the 
unreacted compounds. The product $\left(\mathrm{dPG}-\mathrm{C}_{11}\right)$ was obtained as a white and highly viscose compound after evaporation of methanol by rotary evaporator. Degree of functionalization was determined by ${ }^{1} \mathrm{H}$ NMR in DMF- $\mathrm{d}_{6}$.

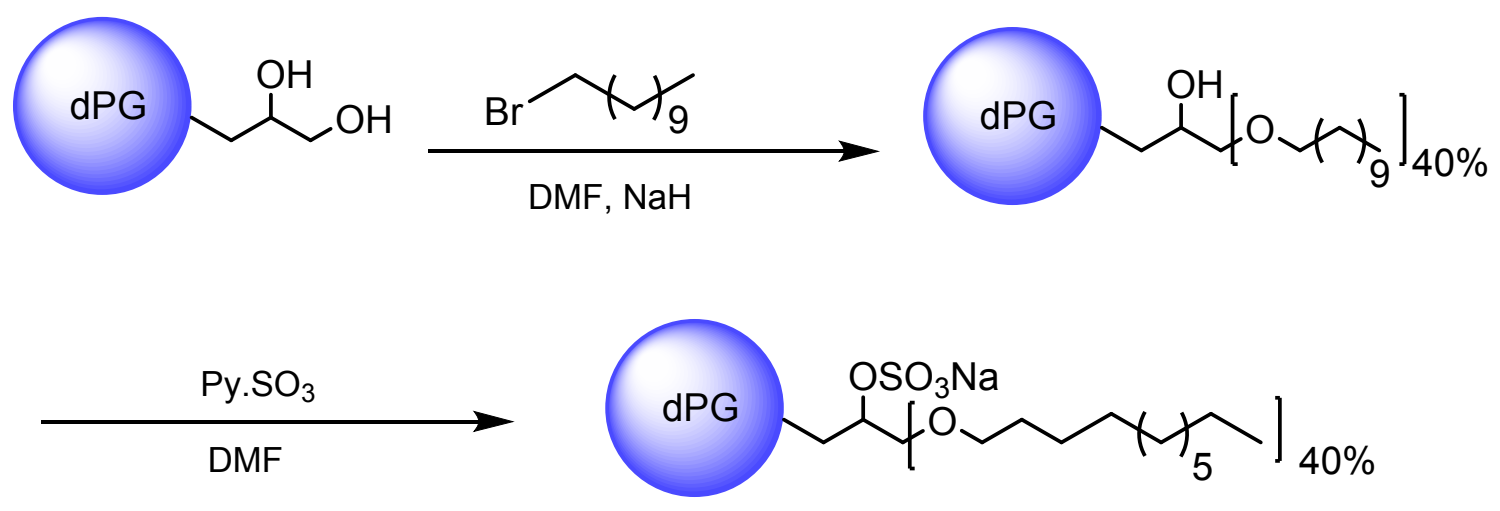

Figure S15. Synthetic route for preparation of the dPG-6.

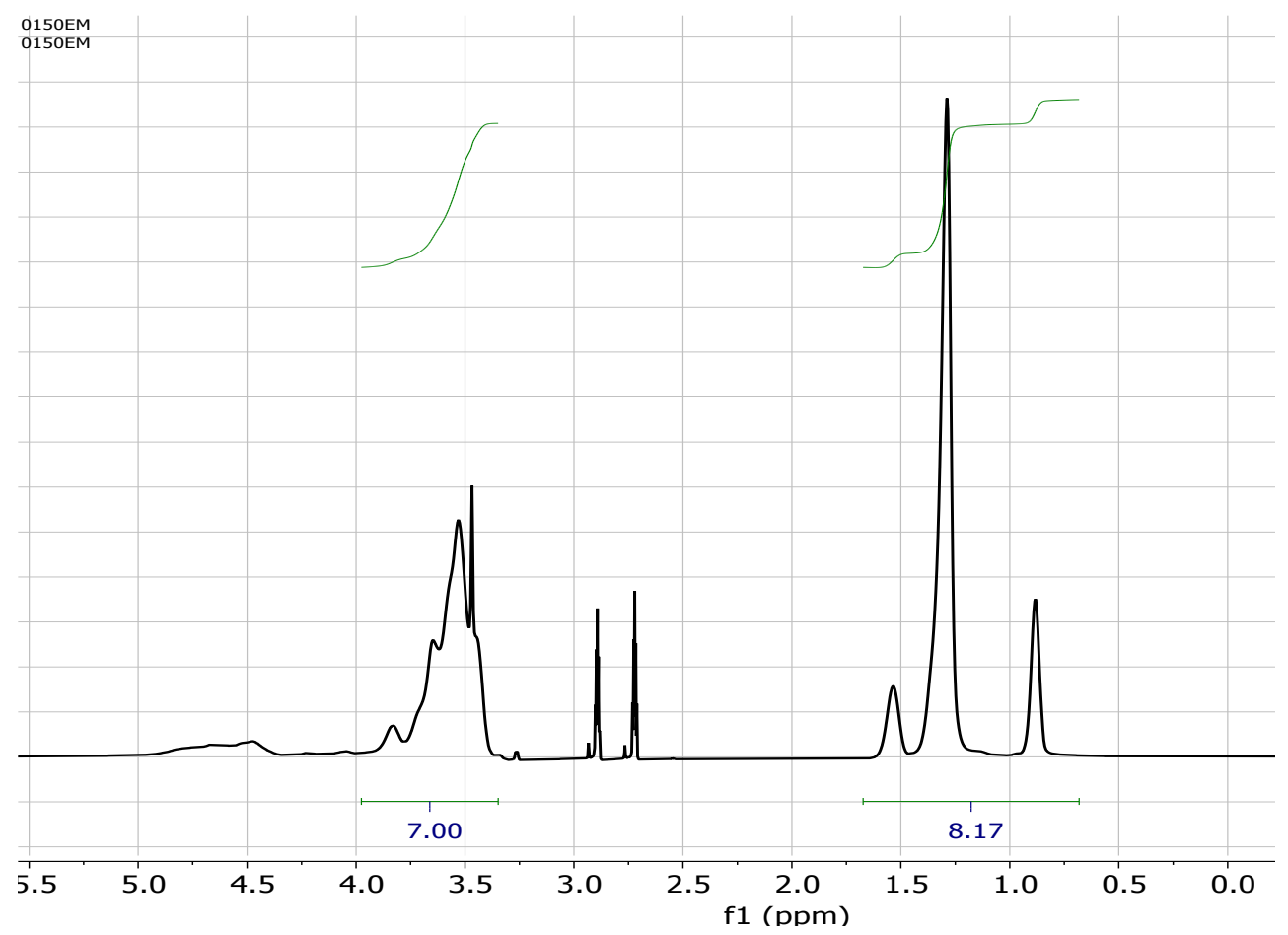

Figure S16. ${ }^{1} \mathrm{HNMR}$ of dPG-6 in DMF-d6 before sulfation. 
In the next the hydroxyl groups on the dPG surface have been sulfated through the reaction with pyridine sulfur trioxide (Py. $\left.\mathrm{SO}_{3}\right)$ complex. For this aim, dPG-C 11 ( $700 \mathrm{mg}, 5.4 \mathrm{mmol} \mathrm{OH}$ to be sulfated) was dried overnight at $60{ }^{\circ} \mathrm{C}$ under vacuum. Dried $\mathrm{dPG}-\mathrm{C}_{11}$ was dissolved in dry DMF (30 mL) under inert atmosphere. To the stirred solution of dPG-C $\mathrm{C}_{11}$ in dry DMF at $60{ }^{\circ} \mathrm{C}, \mathrm{Py} \cdot \mathrm{SO}_{3}$ (1.289 g, $8.1 \mathrm{mmol}, 1.5$ eq.) in dry DMF (5 mL) was added dropwise. The reaction mixture was allowed to stir at $60{ }^{\circ} \mathrm{C}$ overnight. The reaction was quenched with water, and the $\mathrm{pH}$ was adjusted to 8 by addition of $\mathrm{NaOH}$ solution. The mixture was then dialysed against brine using an everdecreasing $\mathrm{NaCl}$ concentration for 2 days, until the medium was changed with distilled water and dialysis continued for 2 more days. ${ }^{4}$ The solvent was decreased under reduced pressure and the product was obtained as a white powder after lyophilisation. The degrees of functionalization (DF) in the different reactions were determined by ${ }^{1} \mathrm{H}$ NMR of the pure product correlating the aliphatic protons at 1.7-0.6 ppm with the polyglycerol backbone protons $(4.4-3.2)$. 


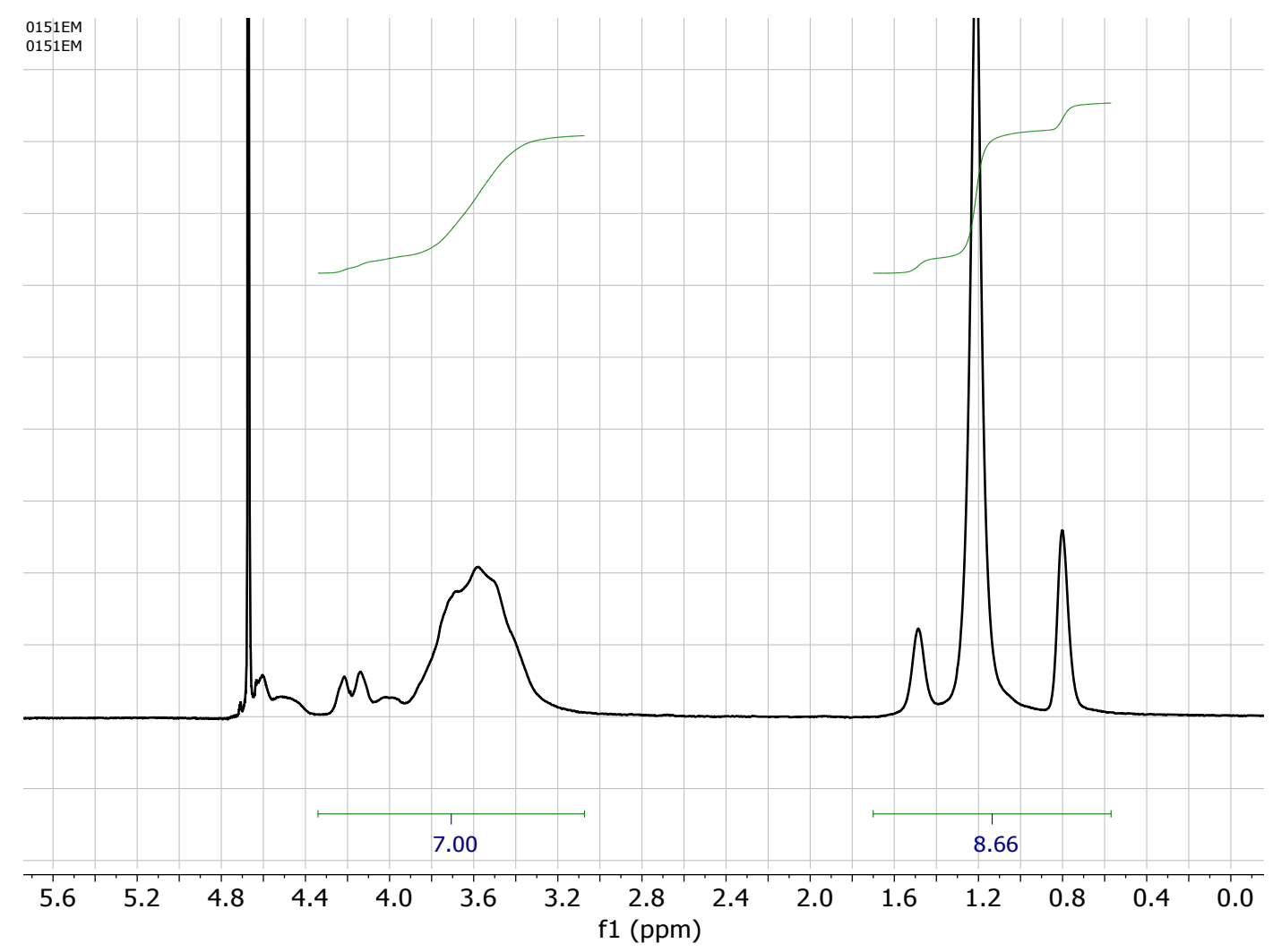

Figure S17. ${ }^{1} \mathrm{HNMR}$ of dPG-6 in $\mathrm{D}_{2} \mathrm{O}$ after sulfation. 
Table S4. Elemental analysis and molecular weight (Mn) of dPG-6 before and after sulfation. * Mn is calculated based on the degree of functionalization of dPG- 6 which is determined by ${ }^{1} \mathrm{HNMR}$, considering the Mn of starting dPG core $10 \mathrm{kDa}$.

\begin{tabular}{|c|c|}
\hline & dPG-6 \\
\hline $\mathrm{C} \%$ & 38.2 \\
\hline $\mathrm{H} \%$ & 6.5 \\
\hline $\mathrm{N} \%$ & 0.0 \\
\hline $\mathrm{S} \%$ & 6.5 \\
\hline $\mathrm{Mn}^{*}$ & 29 \\
\hline
\end{tabular}

\section{Synthesis of dPG-7 and dPG-8}

Through the one-step ring opening functionalization of dPG by using 1,4-Butane sultone and 1,3Propanediol cyclic sulfate and 1,4-butane sultone dPG9 and dPG10 with short alkyl chain have been synthesized respectively. $\mathrm{dPG}(100 \mathrm{mg}, 1.35 \mathrm{mmol} \mathrm{OH}$ to be functionalized) was dried at 60 ${ }^{\circ} \mathrm{C}$ overnight under high vacuum. Dried dPG was dissolved in dry DMF (5 mL). To the stirred solution of dPG in dry DMF at room temperature, $\mathrm{NaH}(65 \mathrm{mg}, 2.7 \mathrm{mmol}, 2$ eq.) was added. The reaction mixture was allowed to stir for 1 hours at room temperature. At this step for the synthesis of dPG9 1,3-propanediol cyclic sulfate (373.3 mg, $2.7 \mathrm{mmol}, 2$ eq.) and for dPG10, 1,4-butane sultone ( $276 \mu \mathrm{L}, 2.7 \mathrm{mmol}, 2$ eq.) were added to the reaction and the reaction was stirred overnight at room temperature. The mixture was then dialysed against brine using an ever-decreasing $\mathrm{NaCl}$ concentration for 2 days, until the medium was changed with distilled water and dialysis continued 
for 2 more days. The solvent was decreased under reduced pressure and the product was obtained as crystalline powder after lyophilisation. The degrees of functionalization (DF) in the different reactions were determined by ${ }^{1} \mathrm{H}$ NMR of the pure product correlating the aliphatic protons at 1.9$1.5 \mathrm{ppm}$ with the polyglycerol backbone protons $(4.2-3.2)$.

a)
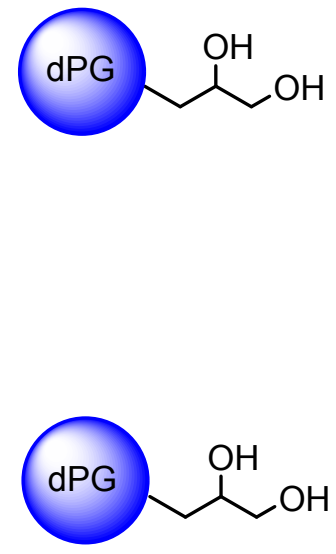

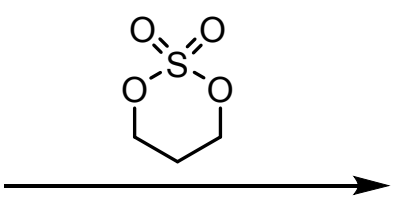

1. $\mathrm{DMF}, \mathrm{NaH}$

2. $\mathrm{NaCl}$

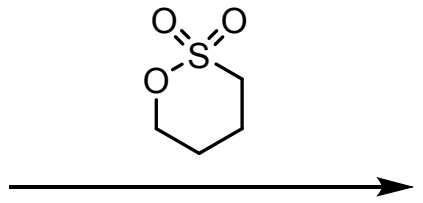

1. DMF, $\mathrm{NaH}$

2. $\mathrm{NaCl}$
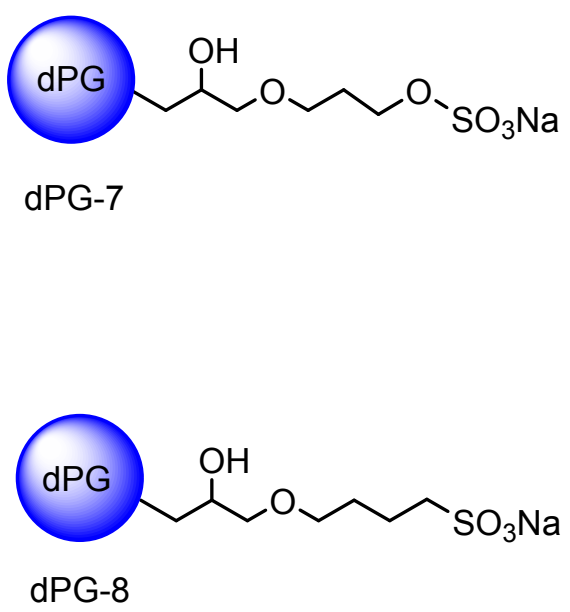

Figure S18. One-pot approach for the synthesis of the a) dPG-7 b) dPG-8. 


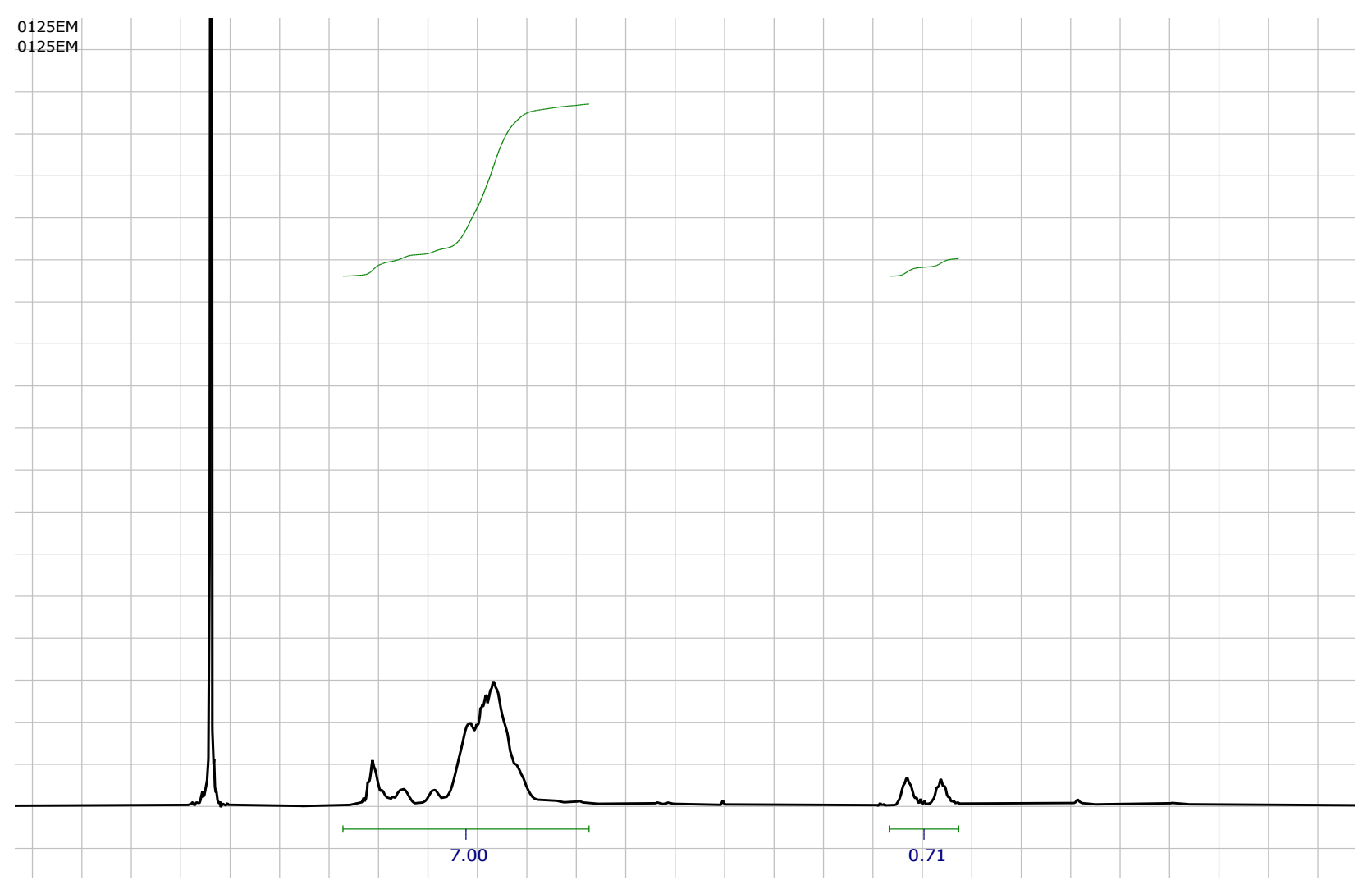

5.45 .25 .04 .84 .64 .44 .24 .03 .83 .63 .43 .23 .02 .82 .62 .42 .22 .01 .81 .61 .41 .21 .00 .80 .60 .40 .2 f1 (ppm)

Figure S19. ${ }^{1} \mathrm{HNMR}$ of $\mathrm{dPG}-7$ in $\mathrm{D}_{2} \mathrm{O}$. 


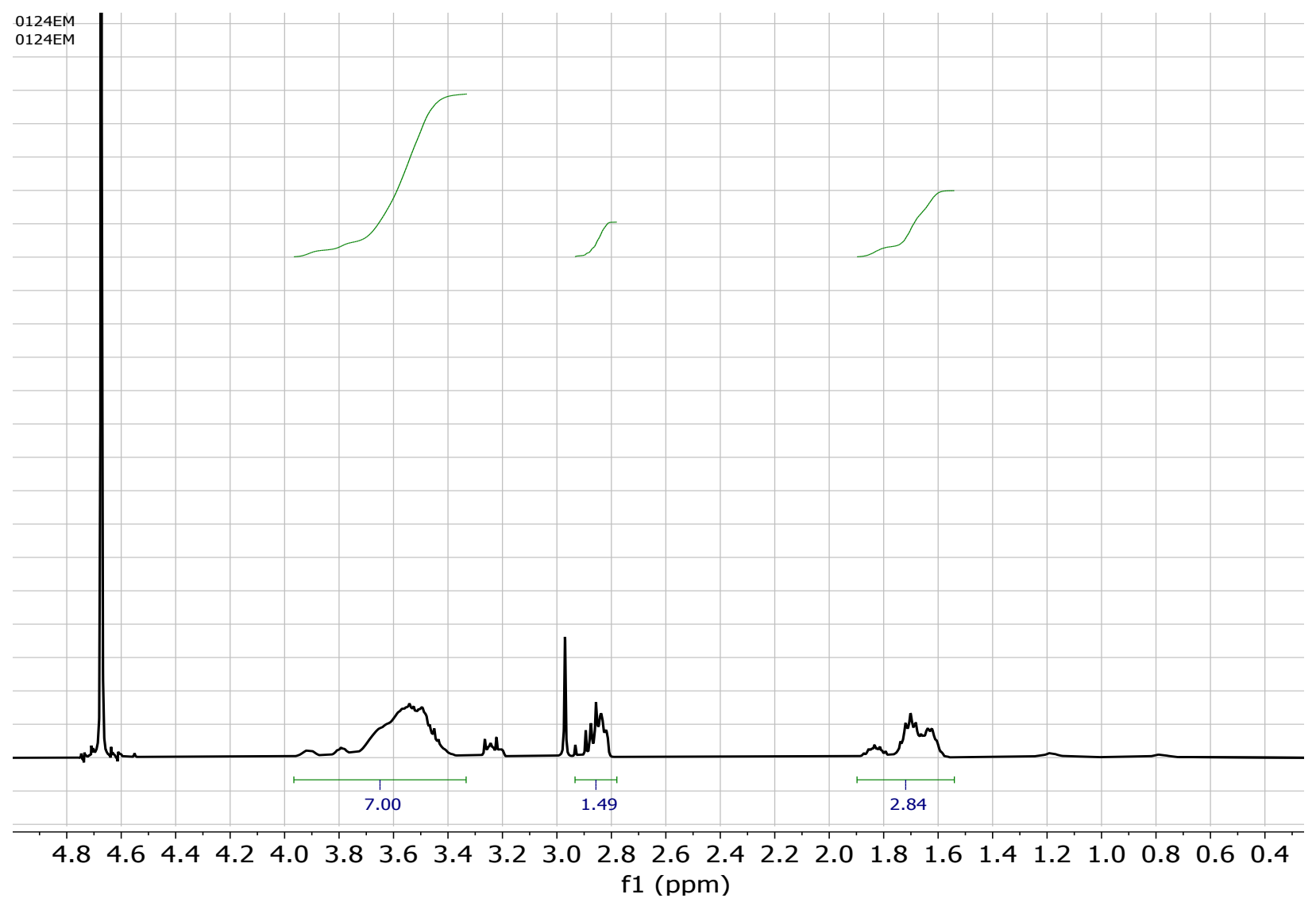

Figure S20. ${ }^{1} \mathrm{HNMR}$ of dPG-8 in $\mathrm{D}_{2} \mathrm{O}$. 
Table S5. Elemental analysis and molecular weight (Mn) of dPG-7 and dPG-8 before and after sulfation. * Mn is calculated based on the degree of functionalization of dPG- 6 which is determined by ${ }^{1} \mathrm{HNMR}$, considering the Mn of starting dPG core $10 \mathrm{kDa}$.

\begin{tabular}{|c|c|c|}
\hline & dPG-7 & dPG-8 \\
\hline $\mathrm{C} \%$ & 35.7 & 38.1 \\
\hline $\mathrm{H} \%$ & 6.8 & 6.2 \\
\hline $\mathrm{N} \%$ & 0.0 & 0.0 \\
\hline $\mathrm{S} \%$ & 8.0 & 11.8 \\
\hline $\mathrm{Mn} *$ & 20 & 25 \\
\hline
\end{tabular}

\section{Antiviral and virucidal activity of the functionalized dPGs.}

Table S6. In the following table all the dose-response curve and the virucidal assay results for all the $\mathrm{dPG}$ reported in Table1 against HSV-2 are shown.

\begin{tabular}{|c|c|c|}
\hline Compound & Dose-Response & Virucidal assay \\
\hline $\mathrm{dPG}$ & 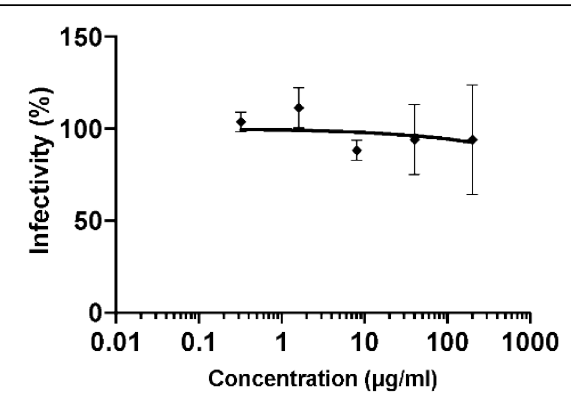 & n.a. \\
\hline
\end{tabular}




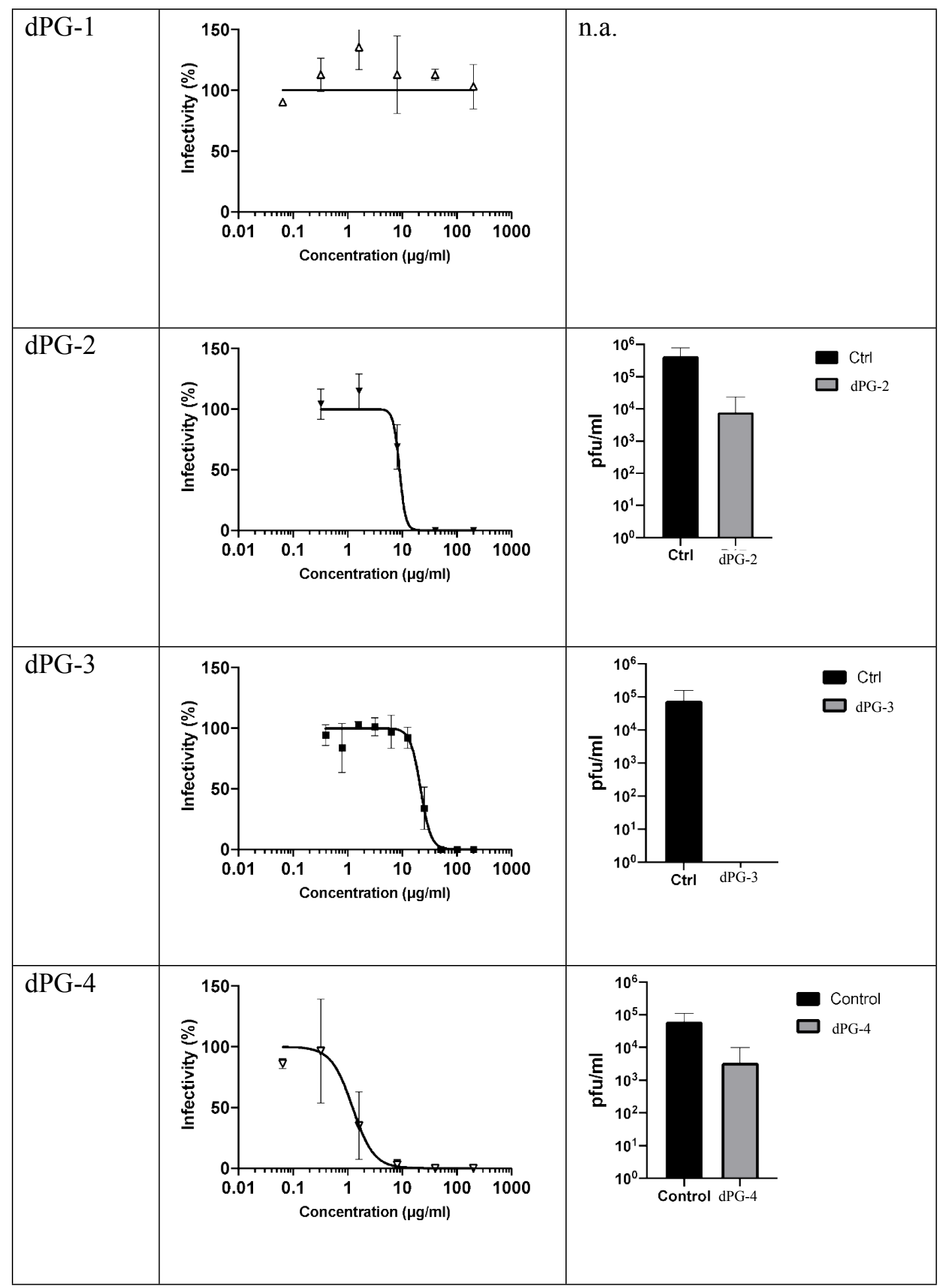




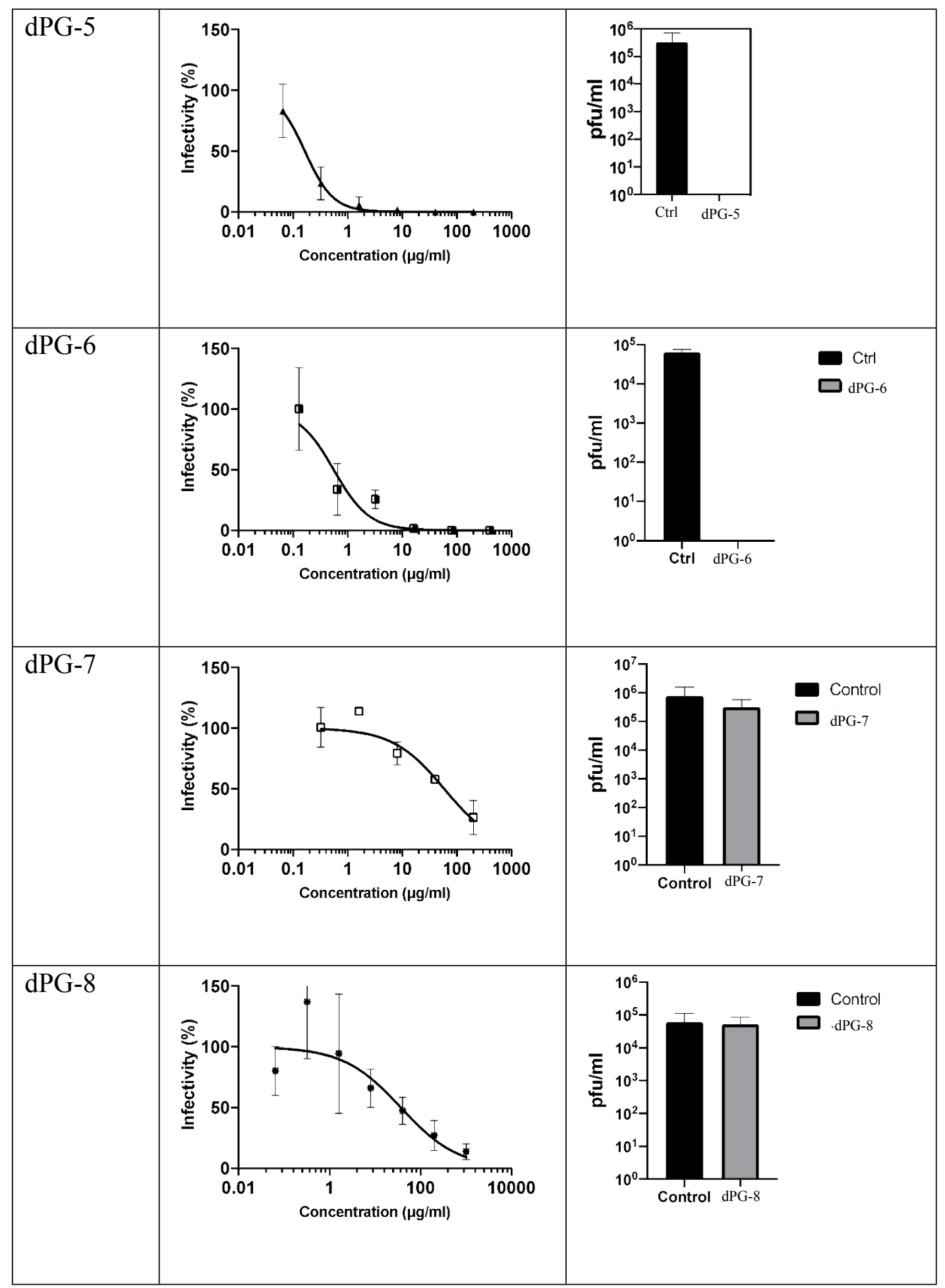


1. Sunder, A.; Frey, H.; Muelhaupt, R., Hyperbranched polyglycerols by ring-opening multibranching polymerization. Macromol Symp 2000, 153 (1), 187-196.

2. Haag, R.; Sunder, A.; Stumbe, J.-F., An approach to glycerol dendrimers and pseudodendritic polyglycerols. J Am Chem Soc 2000, 122 (12), 2954-2955.

3. Guven, Z. P.; Silva, P. H. J.; Luo, Z.; Cendrowska, U. B.; Gasbarri, M.; Jones, S. T.;

Stellacci, F., Synthesis and Characterization of Amphiphilic Gold Nanoparticles. J Vis Exp 2019, (149).

4. Ferraro, M.; Silberreis, K.; Mohammadifar, E.; Neumann, F.; Dernedde, J.; Haag, R., Biodegradable Polyglycerol Sulfates Exhibit Promising Features for Anti-inflammatory

Applications. Biomacromolecules 2018, 19 (12), 4524-4533. 